\title{
Development of a Solar Drier for Domestic Applications
}

\author{
Harrison K. Tarus, Ahmed, M. S \\ Department of Mechanical and Production Engineering, University of Eldoret, P.O. Box 1125 Eldoret, Kenya
}

\begin{abstract}
The solar drying system utilizes solar energy to heat up air and to dry small scale domestic produce like grain, omena, vegetables etc. This is beneficial in reducing wastage and hence preservation of agricultural products as well as increasing affordability by the local population who naturally cannot afford the higher cost of mechanical driers. This study presents the design, construction and performance of solar grain dryer. In the dryer, the heated air from a separate solar collector is passed through a grain bed, and at the same time, the drying cabinet absorbs solar energy directly through the transparent walls and roof. Tests carried out on the drier showed that the temperatures inside the dryer and the solar collector were much higher than the ambient temperature during most hours of the daylight. The temperature rise inside drying cabinet was up to $24^{\circ} \mathrm{C}$ (74\%) for about three hours immediately after $12.00 \mathrm{~h}$ (noon). This indicates better performance compared to open sun drying.
\end{abstract}

Keywords—Drier, grains, Solar, Temperature.

\section{INTRODUCTION}

The purpose of drying agricultural produce is to reduce moisture content so that it can be processed safely and stored for increased periods of time [1]. It is estimated that substantial amount of the world's grain production is lost after harvest because of inefficient handling and poor implementation of post-harvest technology. Most grains are sun-dried on the ground, but this process is slow and ineffective because it takes more time to achieve a desired results as well as being unhygienic due to general exposure to the environment.

Solar drying of agricultural produce by forced convection in enclosed structures is one of effective ways of reducing post-harvest losses as well as low quality of dried products associated with the normal traditional open sun drying methods [2]. In most developing nations and especially their rural locations, grid-connected electricity or supplies of any other non-renewable energy sources may be unavailable, too expensive or unreliable. In such circumstances, solar dryers become increasingly attractive as commercial alternatives [3]; [4].

Passive dryers can be applied better for drying small batches of grains as well as fruits and vegetables such as Mangoes, bananas, pineapple, potatoes, carrots etc. [5]

\section{DESIGN AND CONSTRUCTION}

The materials used for the construction of the solar dryer were obtained locally and cheaply. The essential materials included: Well-seasoned wood, transparent glass, wire mesh, aluminium sheet, black paints, pairs of screws, welding rods, SHS metal (square hollow section) ordinary steel, nails and water proof glue

AutoCAD and Civil 3D was used in initial design and analysis of the design. The final design was achieved by fabrication. The fabrication process entailed arc welding for solar grain dryer stand, screwing of the solar cabinet and solar collector. The main parts of the solar dryer included: The drying cabinet, The solar collector. The stand, the drying trays for grain loading

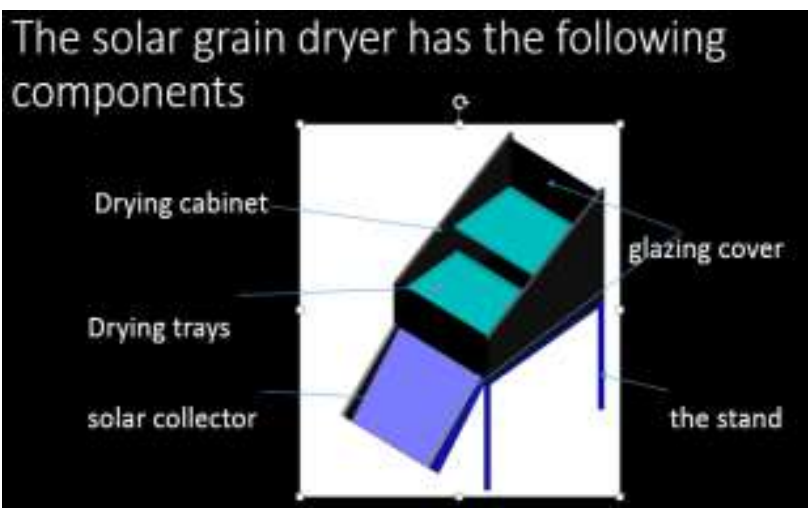

Fig. 3.1: isometric view solar grain drier

i. The drying cabinet

The drying cabinet was made of a well-seasoned wood well fitted by screws with a glazing cover plate.

Inside the cabinet are the drying trays. The cabinet was painted black from inside.

The drying cabinet together with the structural frame of the dryer was built from well-seasoned woods which could withstand termite and atmospheric attacks. An outlet vent was provided towards the upper end at the back of the cabinet to facilitate and control the convection flow of air through the dryer. Access door to the drying chamber was also provided at the back of the cabinet. The top of the cabinet was covered with glass for direct sunlight drying.

ii. The solar collector

It had a simple design, it entailed the cover glazing was made of glass, the absorber plate was made of aluminium 
sheet metal painted black. Also, it was insulated all round with wood. The solar collector had two openings, hence, $\mathrm{A}_{1} \mathrm{~V}_{1}=\mathrm{A}_{2} \mathrm{~V}_{2}$ applying flow rate in a reducing bush in fluid mechanics.

The heat absorber (inner box) of the solar air heater/collector was constructed using $1 \mathrm{~mm}$ thick aluminum plate, painted black, was mounted in an outer box built from well-seasoned woods. The solar collector assembly consists of air flow channel enclosed by transparent cover (glazing). An absorber mesh screen midway between the glass cover and the absorber back plate provides effective air heating because solar radiation that passes through the transparent cover is then absorbed by both the mesh and back-plate. The glazing is made of a single layer of $3 \mathrm{~mm}$ thick transparent glass sheet; it has a surface area of $0.2675 \mathrm{~m}^{2}$ and transmittance above 0.7 for wave lengths in the rage $0.2-2.0 \mu \mathrm{m}$ and opaque to wave lengths greater than $4.5 \mu \mathrm{m}$. The effective area of the collector glazing is $0.2675 \mathrm{~m}^{2}$. One end of the solar collector has an air inlet vent of area $0.056 \mathrm{~m}^{2}$ which was covered by a wire mesh to prevent entrance of rodents.

\section{iii. The stand}

The stand of the grain dryer was made of ordinary steel tube (square hollow section) which had desired strength for that purpose.

\section{iv. Drying trays}

The trays had a simple design. They were made of a layer of wire mesh mounted on a wooden framing.
The dryer is a passive system in the sense that it has no moving parts. It is energized by the sun's rays entering through the collector glazing. The trapping of the rays is enhanced by the inside surfaces of the collector that were painted black and the trapped energy heats the air inside the collector. The greenhouse effect achieved within the collector drives the air current through the drying chamber. If the vents are open, the hot air rises and escapes through the upper vent in the drying chamber while cooler air at ambient temperature enters through the lower vent in the collector. Therefore, an air current is maintained, as cooler air at a temperature $T_{\text {inlet }}$ enters through the lower vents and hot air at a temperature $T_{\text {outlet }}$ leaves through the upper vent.

\section{RESULTS AND ANALYSIS}

A solar drier was fabricated complete with required specifications before testing temperatures variations in solar collector and drying cabinet as compared to the ambient temperature. It was established that; The dryer is hottest about mid-day when the sun is usually overhead. The temperatures inside the dryer and the solar collector were much higher than the ambient temperature during most hours of the daylight. The temperature rise inside drying cabinet was up to $24^{\circ} \mathrm{C}(74 \%)$ for about three hours immediately after $12.00 \mathrm{~h}$ (noon). This indicates better performance compared to open sun drying.

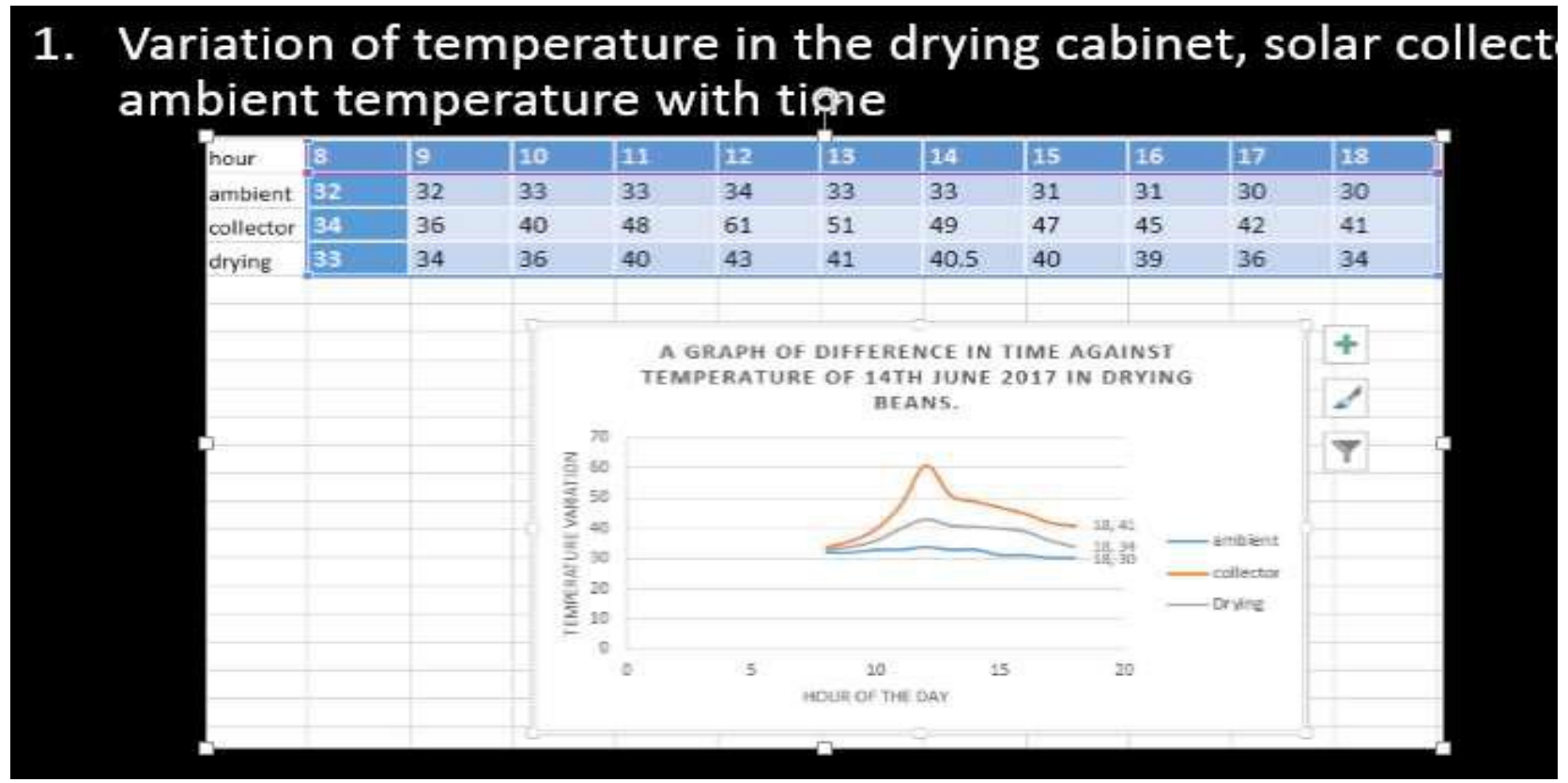

Fig. 3.1: Variations of Temp in the drying cabinet, solar collector and ambient temperature with time

\section{CONCLUSION}

From the test done, it can concluded that the solar dryer can raise the ambient air temperature to a higher considerable value for drying agricultural crops. The hourly variation of the temperatures inside the cabinet and air-heater are much higher than the ambient temperature during the most hours of the day-light. The temperature rise inside the drying cabinet was up to $24^{\circ} \mathrm{C}$ (74\%) for about three hours immediately after $12.00 \mathrm{~h}$ (noon). The dryer exhibited sufficient ability to dry agricultural 
produce reasonably rapidly to a safe moisture level and simultaneously it ensures a superior quality of the dried product. In addition the products inside the dryer required less attentions, like attack of the product by rain or pest (both human and animals), compared with those in the open sun drying. Although it was used to dry grain, the drier can also be used in other crops like yams, cassava and plantain and other food products e.g. Omena. There is ease in monitoring when compared to the natural sun drying technique. The capital cost involved in the construction of a solar dryer was much lower to that of a mechanical dryer because of use of locally available materials.

\section{ACKNOWLEDGEMENTS}

Appreciation to our colleagues at the University of Eldoret for their moral support and positive criticism during the entire study.

\section{REFERENCES}

[1] Mujumdar, A.S., 2007, Handbook of Industrial drying, Taylor and Francis group, U.K.

[2] Jain, D., Tiwari, G. N., 2003, Thermal aspects of open sun drying of various crops, Energy 28, pp. 3754.

[3] Mekhilefa, S., Saidurb, R., Safari, A., 2011, A review on solar energy use in industries Renewable and Sustainable Energy Reviews,15, pp. 1777-1790.

[4] Xingxing, Z., Xudong, Z., Stefan, S., Jihuan, X., Xiaotong, Y., 2012, Review of R\&D progress and practical application of the solar photovoltaic/thermal (PV/T) technolo-gies, Renewable and Sustainable Energy Reviews, 16, pp. 599-617.

[5] Hughes, B. R., Oates, M., 2011, Performance investigation of a passive solar assisted kiln in the United Kingdom, Solar Energy, 85, pp. 1488-1498. 